\title{
Successful Use of Extra-corporeal Membrane Oxygenation in a Patient with Streptococcal Sepsis: A Case Report and Review of Literature
}

\author{
Michal Pořízka1, Petr Kopecký ${ }^{1}$,Tomáš Prskavec² , Jan Kunstýŕr ${ }^{1}$, \\ Jan Rulíšek', Martin Balík ${ }^{1}$ \\ ${ }^{1}$ Department of Anaesthesiology and Intensive Care, First Faculty of Medicine, \\ Charles University in Prague and General University Hospital in Prague, Prague, \\ Czech Republic; \\ ${ }^{2} 2^{\text {nd }}$ Department of Surgery - Department of Cardiovascular Surgery, First \\ Faculty of Medicine, Charles University in Prague and General University Hospital \\ in Prague, Prague, Czech Republic \\ Received November 23, 2014; Accepted March 12, 2015.
}

Key words: Extra-corporeal membrane oxygenation - Septic shock Cardiomyopathy - Streptococcal sepsis - Heart failure

\begin{abstract}
A young patient with streptococcal sepsis due to the phlegmon of his left thigh was admitted to the general intensive care unit. He developed a multi-organ failure and septic cardiomyopathy with subsequent cardiogenic shock. This resulted in hemodynamic instability unresponsive to conservative medical treatment. We report a successful application of veno-arterial extra-corporeal membrane oxygenation, which was used to overcome the period of critically low cardiac output caused by severe septic myocardial dysfunction.
\end{abstract}

The echocardiographic monitoring was supported in part from project reg. no. CZ.2.16/3.1.00/21565 from OP Prague Competitiveness.

Mailing Address: Michal Pořízka, MD., PhD., E.D.I.C., Department of Anesthesiology and Intensive Care, First Faculty of Medicine, Charles University in Prague and General University Hospital in Prague, U Nemocnice 2, 12808 Prague 2, Czech Republic; Mobile Phone: +420 606945 580; e-mail: rizko@post.cz 


\section{Case report}

A thirty-one-year old male (height $176 \mathrm{~cm}$, weight $58 \mathrm{~kg}$ ) with no previous medical history presented with exercise-induced rupture of quadriceps femoris muscle to the regional hospital. He was treated conservatively, however within 24 hours the injured thigh developed severe phlegmon. After another day of conservative treatment with antibiotics (clindamycine) his clinical condition worsened with the onset of sepsis, which was associated with progressive dyspnoea, tachycardia and significant rise of inflammatory markers. Due to this rapid and life threatening deterioration he was referred to our tertiary university hospital for a multidisciplinary care. On presentation, he was fully conscious, hemodynamically stable with normal blood pressure $(100 / 60 \mathrm{~mm} \mathrm{Hg})$ and tachycardia $(130 / \mathrm{min})$. However, hyperlactataemia $(3.6 \mathrm{mmol} / \mathrm{l})$, metabolic acidosis (base excess of $-6.2 \mathrm{mmol} / \mathrm{l}$ ) and central venous blood oxygen desaturation (54\%) were noted, signalling significant tissue hypoxia. Myoglobin $(12000 \mu \mathrm{g} / \mathrm{l})$ and procalcitonin $(11 \mu \mathrm{g} / \mathrm{l})$ levels were markedly increased, suggesting ongoing rhabdomyolysis of infected thigh muscles and presence of bacterial infection, respectively. Immediate transthoracic echocardiogram revealed profound diffuse hypokinesis and severely depressed systolic function of the left ventricle (LV) with ejection fraction (EF) of $19 \%$, normal right ventricular function and no valvular abnormalities. Measured stroke volume index was severely lowered $\left(16 \mathrm{ml} / \mathrm{m}^{2}\right)$. Troponin I concentrations were slightly increased $(0.07 \mu \mathrm{g} / \mathrm{l})$ and electrocardiogram only showed sinus tachycardia without ischemic changes. All these findings supported the diagnosis of septic cardiomyopathy. Levosimendan infusion $(0.2 \mu \mathrm{g} / \mathrm{kg} / \mathrm{min})$ was commenced and shortly after admission patient underwent urgent medial fasciotomy of the left thigh in an attempt to control the infection source. Unfortunately, no localized fluid collection for eventual drainage was found. After the surgical procedure patient remained intubated and mechanically ventilated. Within a few hours, he became hemodynamically unstable with massive increase in vasopressor support $(1 \mu \mathrm{g} / \mathrm{kg} /$ $\mathrm{min}$ of norepinephrine and 4 units/hour of vasopressin). Serial echocardiographic examinations were carried out with the finding of an improvement in LV function (EF 35\%) and with signs of fluid responsiveness (respiratory collapsibility of inferior vena cava of 50\%). Further fluid loading was initiated. However several hours later, on day 2, LV function started to deteriorate again with gross hemodynamic instability and progression of tissue hypoxia. Thus, it was decided to initiate a venoarterial membrane oxygenation (ECMO) as the last option to save patient's life.

ECMO venous drainage cannula $20 \mathrm{~F}$ and arterial return cannula $18 \mathrm{~F}$ (both Duraflo Edwards Lifesciences, Irviene, CA, USA) were inserted through right femoral vessels and a distal reperfusion catheter (6F) was also inserted in femoral artery in order to prevent distal limb ischemia. ECMO (centrifugal pump Maquet Rotaflow RF 32, Maquet Cardiopulmonary AG, Hirrlingen, Germany) was successfully instituted and blood flow of $5 \mathrm{l} / \mathrm{min}$ was maintained with immediate improvement of patient's condition. An abrupt deescalation of vasopressor 


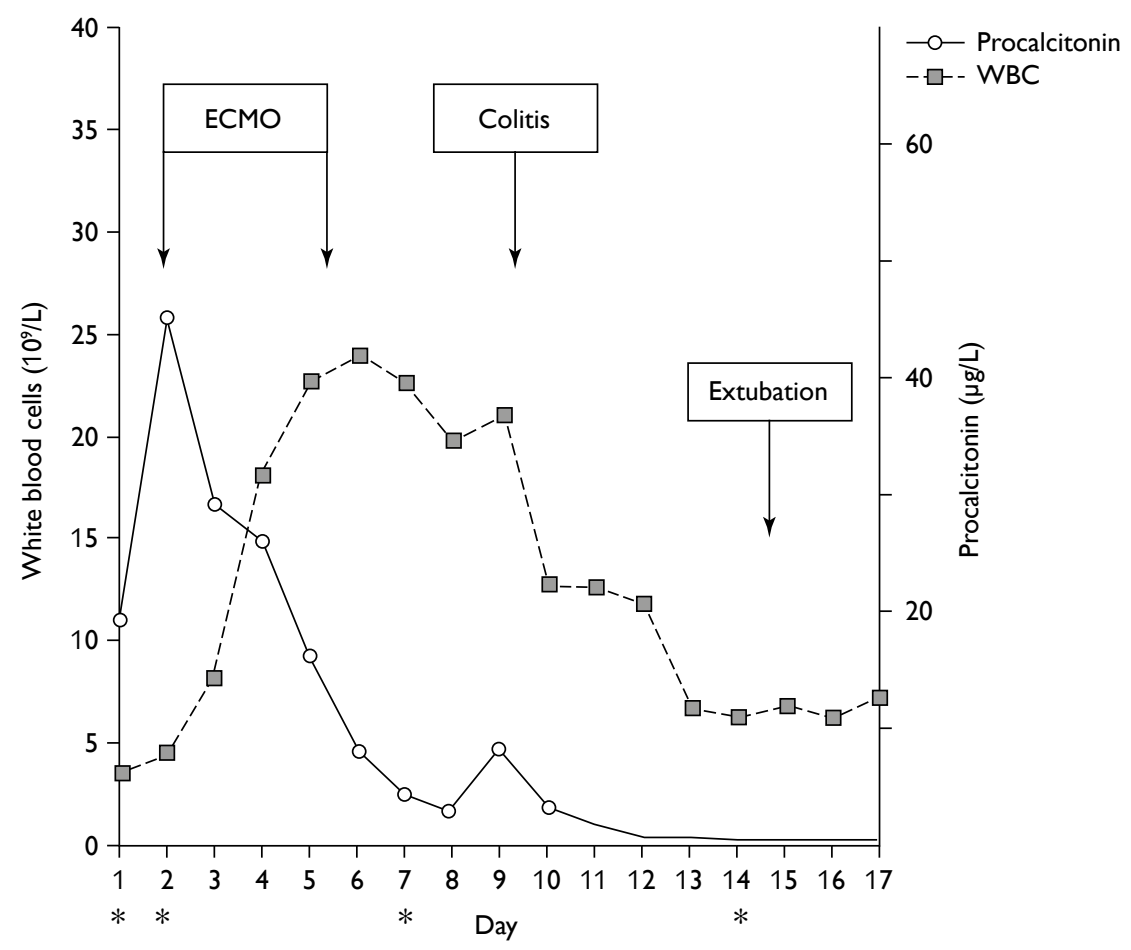

Figure 1 - Levels of inflammatory parameters with the depiction of major events from the admission to day 17. Depicted stars along the $x$-axis represent the time of surgical explorations; ECMO - extra-corporeal membrane oxygenation; WBC - white blood cells.

support and normalization of lactate and acid base status followed. Due to the worsening of the limb phlegmon a lateral thigh fasciotomy was performed. Streptococcus pyogenes resistant to clindamycine was finally cultured from multiple haemocultures and was identified as a causative agent. Adjustment of the antibiotic therapy was made (a switch to penicillin G, piperacilin-tazobactam and vankomycine) with subsequent clinical improvement and decrease of inflammatory markers further on (Figure 1). Also LV systolic function gradually improved back to normal and patient was successfully weaned off and finally disconnected from extracorporeal circulation after 96 hours of ECMO on day 5. In further course of the disease a few complications followed. Patient developed colitis (confirmed by CT scan) with recurrence of sepsis and further antibiotic treatment escalation had to be made (meropenem and metronidazole were added) on day 8. After a few days colitis resolved and no surgical exploration of the abdomen was needed. Another complication involved the thrombosis of common and external iliac veins and an inferior vena cava filter was inserted to prevent pulmonary embolism on day 11. Meanwhile patient underwent repeated surgical explorations and necrectomies of his left thigh. Initially high myoglobin levels 
spontaneously decreased and patient suffered only transient acute kidney injury of moderate severity without a need for dialysis. After successful management of these complications patient was extubated on day 15 and finally dismissed from intensive care to general surgical ward on day 21. Nevertheless, the healing of the wound was still very complicated and required a reconstructive surgery with fasciocutaneous flap transposition on day 50. After another month of local surgical therapy he was finally discharged from hospital to the home care on day 93.

\section{Discussion}

Sepsis represents a complex disease as a manifestation of the immune and inflammatory response to infection and still remains the leading cause of death in critically ill patients (Vincent et al., 2006). Severe sepsis is defined as sepsis with organ dysfunction, while septic shock is sepsis with hypotension that persists despite fluid resuscitation (Dellinger et al., 2013). The incidence of severe sepsis and septic shock is increasing with a mortality exceeding $50 \%$ of the latter (Vincent et al., 2006). Recent definitions recognize the importance of myocardial depression and include a low cardiac output (CO) or echocardiographic evidence of cardiac dysfunction as one of the criteria for diagnosis of severe sepsis (Annane et al., 2005). Adequately resuscitated patients with severe sepsis display a hyperdynamic circulation with low systemic vascular resistance, and high CO. However, despite the maintenance of a normal stroke volume, many patients suffer from intrinsic myocardial dysfunction. This may result in reduction in ejection fraction (EF) (Price et al., 1999) and hypodynamic septic shock. Although earlier studies reported that impaired LV EF in and LV dilatation in septic patients had a good prognosis, recent studies using echocardiography showed that an impaired LV EF was also associated with a poor prognosis (Charpentier et al., 2004). It seems that the problem is more related to a sepsis related dilatation and remodelation of left ventricle than to LV EF itself (Huang et al., 2013b). Although CO is maintained or even elevated during septic shock, cardiac dysfunction can be demonstrated in up to $60 \%$ of patients (Vieillard-Baron et al., 2008). The mechanisms underlying this myocardial depression have not been fully elucidated; however, it is likely that cytokines and nitric oxide have major roles in its etiopathogenesis (Romero-Bermejo et al., 2011). Myocardial depression reaches its maximum at 48 hours after the onset of sepsis with subsequent gradual normalization of LV function in survivors (Hunter and Doddi, 2010). Furthermore, mild elevation of cardiac troponin concentrations in patients with septic shock with no evidence of coronary artery disease has been shown to be an indicator of LV dysfunction and is associated with a worse prognosis (Mehta et al., 2004).

The management of sepsis-induced myocardial dysfunction (sometimes called septic cardiomyopathy) remains supportive. Persistent myocardial dysfunction despite adequate fluid management may require inotropic support. Dobutamine remains the most widely used inotrope, however there is an increasing trend 
towards the use of the calcium-sensitizing agent levosimendan (Hunter and Doddi, 2010). In uncontrollable sepsis with the development of refractory cardiogenic shock (i.e. hypodynamic septic shock) unresponsive to a conventional inotropic support, mechanical heart support represents the last rescue therapy to restore a stable hemodynamic state. Intra-aortic balloon pump and ECMO have been used to bridge such a catastrophic hemodynamic deterioration in patients with septic cardiomyopathy (MacLaren and Butt, 2007; Romero-Bermejo et al., 2011).

Extracorporeal membrane oxygenation is the use of a modified extracorporeal circulation (ECC) circuit to provide support for severe, reversible respiratory or cardiac failure. The first successful clinical application of ECMO was reported in 1972 in an adult patient with acute respiratory distress syndrome (ARDS) following a traffic accident (Mielck and Quintel, 2005). ECMO was then used in patients of different ages including neonatal patients. An ECMO circuit consists of vascular access cannulas, tubing, pump (centrifugal or roller) and an oxygenator.Veno-venous cannulation is used for respiratory failure, and veno-arterial cannulation (VA) for circulatory failure or combined cardiorespiratory failure. In VA ECMO, the drainage cannula is placed in the inferior vena cava or right atrium. This can be done either via a sternotomy or percutaneously by inserting the cannula via the internal jugular or the femoral vein. Blood is returned to the patient through a cannula inserted in either the femoral artery (peripheral ECMO) surgically or percutaneously, or in the ascending aorta (central ECMO) surgically. Adequate anticoagulation is required to prevent the clotting of ECMO circuit. That is normally achieved by unfractionated heparin infusion, targeting the activated partial thromboplastin time of $60-80$ seconds. The clinical management of patients requiring ECMO is very complex and best performed by an experienced team in a specialized centre (Combes et al., 2014).

Although traditionally not regarded as appropriate ECMO candidates, patients with sepsis can also be supported. The two important manifestations of sepsis that may require ECMO are ARDS, being the most common indication (Peek et al., 2009), and septic shock (Huang et al., 2013a). The sepsis with cardiovascular collapse due to septic cardiomyopathy and development of hypodynamic septic shock is a less common indication and is associated with a poorer prognosis than other conditions. There is a large body of evidence that ECMO provides adequate tissue oxygen delivery in neonatal and paediatric patients suffering cardiac and respiratory failure, or both (MacLaren and Butt, 2007). Therefore, for septic shock refractory to all conventional measures, the American College of Critical Care Medicine has even suggested that ECMO is a viable therapy in neonates and children (Carcillo et al., 2002). On the contrary, although successful use of ECMO in adult septic cardiomyopathy has been reported in a few cases (Vohra et al., 2009) and in recent case series (Brechot et al., 2013), the experience with ECMO in adults with septic shock still remains very limited. The major limitation concerns conditions with severely reduced systemic vascular resistance in combination with 
inadequately low cardiac output, where even maximal ECMO blood flow may not restore adequate cardiac index nor perfusion pressure.

This report describes the successful use of ECMO therapy in an adult patient with septic shock resulting in severe cardiac dysfunction. Its application helped to bridge the critical period of overt sepsis with cardiac failure and enabled restoration of adequate whole body oxygen delivery. This earned time for the antibiotics to start working efficiently and in combination with timely surgical therapy it finally enabled us to gain control over sepsis. In conclusion, we recommend that VA ECMO should be used in an adult patient with refractory septic shock and severe myocardial dysfunction leading to a life-threatening, low cardiac output state.

\section{References}

Annane, D., Bellissant, E., Cavaillon, J. M. (2005) Septic shock. Lancet 365, 63-78.

Brechot, N., Luyt, C. E., Schmidt, M., Leprince, P., Trouillet, J. L., Leger, P., Pavie, A., Chastre, J., Combes, A. (2013) Venoarterial extracorporeal membrane oxygenation support for refractory cardiovascular dysfunction during severe bacterial septic shock. Crit. Care Med. 41, 1616-1626.

Carcillo, J. A., Fields, A. I.; American College of Critical Care Medicine Task Force Committee Members

(2002) Clinical practice parameters for hemodynamic support of pediatric and neonatal patients in septic shock. Crit. Care Med. 30, 1365-1378.

Charpentier, J., Luyt, C. E., Fulla, Y., Vinsonneau, C., Cariou, A., Grabar, S., Dhainaut, J. F., Mira, J. P., Chiche, J. D. (2004) Brain natriuretic peptide: A marker of myocardial dysfunction and prognosis during severe sepsis. Crit. Care Med. 32, 660-665.

Combes, A., Brodie, D., Bartlett, R., Brochard, L., Brower, R., Conrad, S., De Backer, D., Fan, E., Ferguson, N., Fortenberry, J., Fraser, J., Gattinoni, L., Lynch, W., MacLaren, G., Mercat, A., Mueller, T., Ogino, M., Peek, G., Pellegrino, V., Pesenti, A., Ranieri, M., Slutsky, A., Vuylsteke, A.; International ECMO Network (ECMONet) (2014) Position paper for the organization of extracorporeal membrane oxygenation programs for acute respiratory failure in adult patients. Am. J. Respir. Crit. Care Med. 190, 488-496.

Dellinger, R. P., Levy, M. M., Rhodes, A., Annane, D., Gerlach, H., Opal, S. M., Sevransky, J. E., Sprung, C. L., Douglas, I. S., Jaeschke, R., Osborn, T. M., Nunnally, M. E., Townsend, S. R., Reinhart, K., Kleinpell, R. M., Angus, D. C., Deutschman, C. S., Machado, F. R., Rubenfeld, G. D., Webb, S. A., Beale, R. J., Vincent, J. L., Moreno, R.; Surviving Sepsis Campaign Guidelines Committee including the Pediatric Subgroup (2013) Surviving sepsis campaign: International guidelines for management of severe sepsis and septic shock, 2012. Crit. Care Med. 41, 580-637.

Huang, C. T., Tsai, Y. J., Tsai, P. R., Ko,W. J. (2013a) Extracorporeal membrane oxygenation resuscitation in adult patients with refractory septic shock. J.Thorac. Cardiovasc. Surg. 146, 1041-1046.

Huang, S. J., Nalos, M., McLean, A. S. (2013b) Is early ventricular dysfunction or dilatation associated with lower mortality rate in adult severe sepsis and septic shock? A meta-analysis. Crit. Care 17, 96.

Hunter, J. D., Doddi, M. (2010) Sepsis and the heart. Br. J. Anaesth. 104, 3-11.

MacLaren, G., Butt, W. (2007) Extracorporeal membrane oxygenation and sepsis. Crit. Care Resusc. 9, 76-80.

Mehta, N. J., Khan, I. A., Gupta, V., Jani, K., Gowda, R. M., Smith, P. R. (2004) Cardiac troponin I predicts myocardial dysfunction and adverse outcome in septic shock. Int. J. Cardiol. 95, 13-17.

Mielck, F., Quintel, M. (2005) Extracorporeal membrane oxygenation. Curr. Opin. Crit. Care 11, 87-93.

Peek, G. J., Mugford, M., Tiruvoipati, R., Wilson, A., Allen, E., Thalanany, M. M., Hibbert, C. L., Truesdale, A.,

Clemens, F., Cooper, N., Firmin, R. K., Elbourne, D.; CESAR trial collaboration (2009) Efficacy and 
economic assessment of conventional ventilatory support versus extracorporeal membrane oxygenation for severe adult respiratory failure (CESAR): a multicentre randomised controlled trial. Lancet $\mathbf{3 7 4}$, 1351-1363.

Price, S., Anning, P. B., Mitchell, J. A., Evans, T.W. (1999) Myocardial dysfunction in sepsis: Mechanisms and therapeutic implications. Eur. Heart J. 20, 715-724.

Romero-Bermejo, F. J., Ruiz-Bailen, M., Gil-Cebrian, J., Huertos-Ranchal, M. J. (2011) Sepsis-induced cardiomyopathy. Curr. Cardiol. Rev. 7, 163-183.

Vieillard-Baron, A., Caille, V., Charron, C., Belliard, G., Page, B., Jardin, F. (2008) Actual incidence of global left ventricular hypokinesia in adult septic shock. Crit. Care Med. 36, 1701-1706.

Vincent, J. L., Sakr, Y., Sprung, C. L., Ranieri, V. M., Reinhart, K., Gerlach, H., Moreno, R., Carlet, J., Le Gall, J. R., Payen, D.; Sepsis Occurrence in Acutely III Patients Investigators (2006) Sepsis in European intensive care units: Results of the SOAP study. Crit. Care Med. 34, 344-353.

Vohra, H. A., Adamson, L., Weeden, D. F., Haw, M. P. (2009) Use of extracorporeal membrane oxygenation in the management of septic shock with severe cardiac dysfunction after Ravitch procedure. Ann. Thorac. Surg. 87, 4-5. 